\title{
Sistema informativo de operação em campo agrícola, baseado na aquisição automática de dados
}

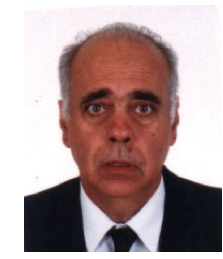

Gastão M. da Silveira' ${ }^{1}$, Fabrizio Mazzetto² \& Savio Landonio ${ }^{3}$

\author{
1 Centro de Mecanização e Automação Agrícola, IAC/SAA, Rod. D. Gabriel, PB, Couto km 65, CP, 26, CEP 13201-970, \\ Jundiaí, SP. Fone (11) 739281-55, Ramal: 195. E-mail: silveira@dea.iac.br (Foto) \\ 2 Instituto de Engenharia Agrícola, Universidade de Milão, Via Celoria 2, 20133, Milão, Itália, Fone: 02/23691432, \\ Fax: 02/23691499. E-mail: fabrizio.mazzetto@unimi.it \\ 3 Instituto de Engenharia Agrícola Universidade de Milão, Via Celoria 2, 20133. E-mail: savio.landonio@unimi.it
}

Protocolo $040-07 / 04 / 2000$

\begin{abstract}
Resumo: Este trabalho apresenta uma proposta de desenvolvimento de um sistema informativo, projetado especificamente para o levantamento dos dados operacionais no campo, o que visa ao gerenciamento da informação na propriedade agrícola. O sistema utiliza ondas de rádio para o reconhecimento automático à distância, de todos os "objetos" existentes no campo (tratorista, trator, implemento e local de trabalho). Os dados levantados, depois de processados, podem ser usados pelo empresário nas atividades de controle, em âmbito diretivo e estratégico. Foram realizados ensaios estáticos, estudando-se os parâmetros de identificação da máquina no campo. $O$ sistema está sendo aperfeiçoado.
\end{abstract}

Palavras-chave: mecanização, identificação, ondas de rádio

\section{An information system based on automatic data recording}

\begin{abstract}
After discussing the aspects related to the information role and management on farms, the paper proposes a solution for the development of an information system specifically designed to collect data from field operations. The system employs radio frequency devices to perform an automatic identification of all the "objects" acting in each field process (worker, tractor, implement, field). Collected data are elaborated and then used by the farmer for management and strategic control activities. Static tests were developed to identify the machine in the field. The system is under further development.
\end{abstract}

Key words: mechanization, identification, radio frequency

\section{INTRODUÇÃO}

No processo produtivo, a informação tem características definidas que devem ser observadas e gerenciadas juntamente com outros fatores de produção. Segundo Nicoletti (1975) a propriedade agrícola, como qualquer outra organização produtiva, pode ser vista como um sistema de atividade, no qual entra uma série de "inputs" (insumos para a produção, informações etc.) que sofrem transformações, originando "outputs" com determinadas características. Os registros dos trabalhos de campo usam, normalmente, métodos pessoais ou pouco organizados, em geral limitados às anotações feitas na caderneta do operador. O levantamento dos dados das operações de campo não é muito difundido. Segundo Misener \& McLeod (1987) existem exemplos de empresas e pesquisadores que se dedicam a esta atividade, seguindo soluções muito práticas que utilizam o tratorista como apontador, além de soluções mais sofisticadas com o emprego de computadores portáteis para o arquivamento dos dados obtidos diretamente no campo. Os dados também podem ser descarregados no fim do dia num computador de mesa, usando-se o processo de código de barras com caneta ótica. Levando-se em consideração esses problemas, Castelli \& Mazzetto (1996) e Mazzetto (1996) desenvolveram um sistema que realiza o registro automático dos dados, a nível de campo, procurando dispor de informações apropriadas para o planejamento e gerenciamento estratégico, de todas as atividades e recursos da propriedade. Este sistema pode muito bem ser utilizado no Brasil na mecanização das principais culturas, como milho, café, cana-de-açúcar, citrus etc.

O objetivo deste trabalho é a realização de ensaios estáticos para definir o comportamento do fenômeno da transmissão/ recepção do código de reconhecimento gerado pelo transmissor, e no qual se baseia a identificação da máquina no sistema proposto. 


\section{MATERIAL E MÉTODOS}

O sistema informativo desenvolvido no Instituto de Engenharia Agrícola da Universidade de Milão, Itália, permite a identificação automática e à distância: assim, os parâmetros seguintes podem ser determinados: velocidade, consumo de combustível e rotação do motor. Em geral, o sistema de identificação automática prevê: a) uma máquina a ser reconhecida, à qual vem afixado um código específico; b) um sistema que identifique o código da máquina, cuja transmissão é feita através de ondas de rádio e atinge o sistema receptor somente quando a máquina se encontra a determinada distância, reconhecendo a máquina , o apontador e o serviço realizado.

O sistema da Figura 1 é caracterizado de acordo com o tipo de objeto a ser reconhecido. $\mathrm{TO}=$ apontador; $\mathrm{TM}=$ máquina; $\mathrm{TA}=$ local de trabalho. $\mathrm{O}$ dispositivo de aquisição de dados montado sobre o trator, é composto de: 1 - uma unidade central de aquisição (UA) na qual convergem todos os dados dos sensores periféricos (velocidade, consumo e rotação do motor) e dos receptores dos códigos transmitidos pelos objetos; 2 - uma memória (DRT) que registra todos os dados provenientes da unidade de aquisição UA. A ligação é feita com um conector, que retira os dados quando se efetua a sua transferência da memória para o computador da fazenda (PC central); 3 - a unidade de recepção colocada na parte da frente do trator (A1) permite a aquisição do código proveniente da fonte transmissora; 4 - a unidade de reconhecimento posterior do trator (A2) possui os mesmos componentes da unidade A1; 5 - um sistema de sensores conectado à unidade UA, é empregado na medição dos principais parâmetros de funcionamento do conjunto trator-máquina: a) medida da velocidade de deslocamento; b) medida do consumo de combustível; c) medida da rotação do virabrequim do motor, usando sistemas já utilizados por diversos pesquisadores e fabricantes como: Auernhammer (1989 e 1993), Bosch (1991), Stone \& Zachos (1993) e Young et al. (1993). No local de trabalho TA deve existir uma pequena antena para realizar a transmissão a uma distância pré-determinada. $\mathrm{O}$ apontador (TO) possui transmissor semelhante aos dispositivos de comando manual anti-furto dos automóveis, conectados fisicamente à chave de partida das várias unidades motrizes.

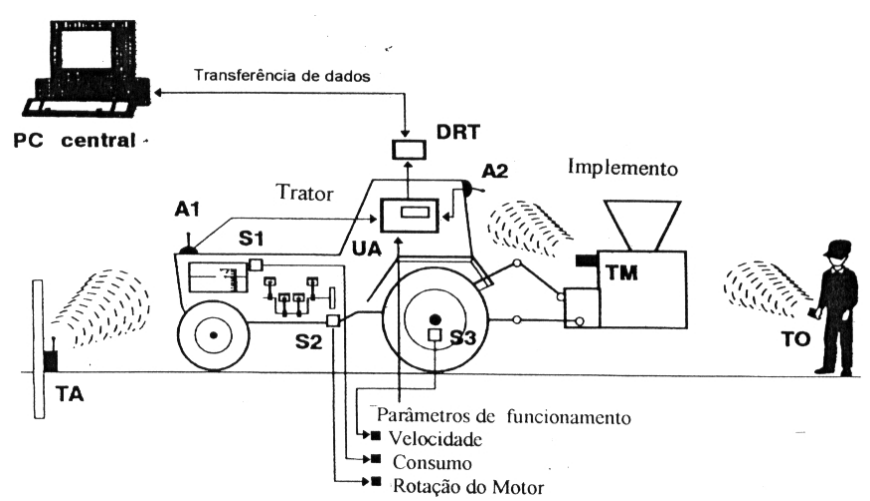

Figura 1. Esquema do sistema de identificação e aquisição de dados

\section{Ensaio estático}

Foram efetuados ensaios verificando-se a influência dos parâmetros construtivos (relativos ao transmissor e à unidade de recepção) estudando-se: antena do transmissor (TA); posicionamento da antena sobre o transmissor; antena A1 da unidade receptora; posicionamento da antena no trator; reconhecimento do implemento (TM); posicionamento da antena receptora do sinal do implemento (A2). Foram estudados, também os parâmetros funcionais relativos à calibração dos equipamentos do sistema (regulagem básica) e os parâmetros concernentes ao projeto do sistema de reconhecimento (tipo de instalação do transmissor no campo) e a interação trator-transmissor.

\section{Parâmetros construtivos}

Antena do transmissor (TA) - o primeiro parâmetro construtivo considerado diz respeito a um componente essencial do sistema de identificação, ou seja, refere-se à antena do transmissor. Com relação à antena procurou-se definir o tipo, comprimento e posicionamento no circuito de transmissão e, quanto ao tipo de antena, os critérios de escolha foram baseados nas necessidades de projeto do aparelho transmissor. Não para o trabalho de campo, antena com forma e dimensões difíceis de se trabalhar, considerando-se os aspectos de robustez, fragilidade etc. Optou-se por se utilizar uma antena normal construída com material metálico, recoberta com resina para proteção contra os agentes atmosféricos. O comprimento de onda escolhido para os ensaios está de acordo com as normas técnicas de rádio, considerando-se factível medida submúltiplo do comprimento de onda de $70 \mathrm{~cm}$; assim, foram realizados ensaios de campo relativos ao comprimento da antena externa ao transmissor, comparando-se as medidas $35,17,5$ e de $8,5 \mathrm{~cm}$.

Posicionamento da antena sobre o transmissor - testou-se o circuito, estando a antena colocada na parte central ou descentralizada em relação ao transmissor.

Antena A1 da unidade receptora - foram realizados ensaios de recepção desta antena.

Posicionamento da antena receptora (A1) no trator - com relação ao posicionamento da antena sobre o trator, foram consideradas duas posições:

- na frente do capo do trator

- e na frente em cima da cabina.

Reconhecimento da máquina (TM) - efetuaram-se ensaios, visando-se verificar o reconhecimento da máquina agrícola. Deve-se observar, neste caso, que a distância na qual o sinal deve ser transmitido, é inferior $(<3 \mathrm{~m})$ curta, quando comparada com a identificação do local de trabalho, e assim sem perturbação de qualquer outro tipo de movimento, motivo pelo qual, o transmissor localizado no implemento (TM) não tem necessidade de amplificar o sinal através da antena.

Posicionamento da Antena A2 - foram feitos ensaios para se definir o posicionamento da antena receptora do sinal do implemento (A2) nas seguintes posições:

- em cima da cabine ou arco de segurança, ou EPCC (Estrutura de Proteção contra Capotagem)

- no pára-lama da roda traseira 


\section{Parâmetros funcionais}

Com relação aos parâmetros funcionais, o item considerado mais importante foi a regulagem da intensidade (filtragem do sinal de recepção). A escala de regulagem adotada durante o ensaio, variou de 600 a $1.200 \mathrm{mV}$ com incrementos de $100 \mathrm{mV}$.

\section{Parâmetros do projeto do sistema}

Estudaram-se os parâmetros relacionados a instalação e ao projeto do sistema. O primeiro parâmetro considerado foi a localização do transmissor da fonte (TA) na área de trabalho. O sistema de aquisição prevê a utilização dos elementos transmissores fixados em determinados pontos (entrada da área, carreadores etc.) além dos relativos aos implementos a serem identificados. A disposição dos elementos transmissores deve ser tal que não seja obstáculo ao trabalho de mecanização.

No primeiro ensaio realizado, verificou-se a possibilidade de se colocar o transmissor rente ao solo, avaliando diversas alturas da antena em relação ao plano horizontal, variando de 4 a $10 \mathrm{~cm}$, com incrementos de $2 \mathrm{~cm}$. A baixa qualidade da transmissão, principalmente em solo úmido, e a pouca proteção e visibilidade do aparelho, concorreram para a desistência desse tipo de utilização.

Foi considerada, também, a possibilidade de se colocar o aparelho acima do solo, mas apoiado sobre um moirão de cimento com $30 \times 30 \times 30 \mathrm{~cm}$. Neste caso, também a eficiência da transmissão foi muito baixa, juntando-se o problema do custo da instalação e abertura do buraco para enterrar o moirão e que demanda tempo em determinados tipos de solo; sendo assim, fez-se opção por utilizar um suporte para apoiar o transmissor, resolvendo o problema, pois permitiu colocar-se o transmissor em uma posição adequada, facilitando também a sua visibilidade.

Durante os ensaios foram testados os seguintes tipos de suporte:

- secção retangular: 30 × 50 × 3 mm com altura de 120 cm (80 $\mathrm{cm}$ fora do solo)

- secção retangular: 50 x 70 x 4 mm com altura de $75 \mathrm{~cm}$ (35 cm fora do solo)

- secção em "L"; 60 x 5 mm com altura de $120 \mathrm{~cm}$ ( $80 \mathrm{~cm}$ fora do solo)

- secção em "U”; 65 x 42 x 5,5 mm com altura de 120 cm (80 $\mathrm{cm}$ fora do solo).

Nas diversas soluções consideradas, foram levantados os diagramas de irradiação, empregando-se transmissores com diferentes tipos de construção.

\section{Ensaio da interação trator-transmissor}

Para complementar os ensaios realizados, foram efetuados testes procurando-se avaliar os efeitos da massa metálica do trator (em condições estáticas) sobre o diagrama de irradiação. Neste caso, o trator foi posicionado no interior de uma malha para levantamento de dados (sinal on/off + valor em $\mathrm{mV}$ - o valor do último sinal revelado). O ensaio foi realizado colocando-se o suporte com o transmissor ao longo dos nós da malha de revelação e se efetuando a leitura dos sinais nos quatro vértices de posicionamento (quatro posições, defasadas de $90^{\circ}$ do transmissor em relação ao trator). A unidade receptora (U A) foi posicionada na parte interna do trator, enquanto a antena receptora (A1) foi colocada em pontos preestabelecidos na própria máquina.
Os ensaios conduzidos consideraram como variáveis a serem testadas:

- modelos e dimensões (Tratores John Deere 4450 e 2850)

- características do transmissor (dimensionamento e colocação da antena)

- tipo de suporte (secção e dimensões)

- orientação do transmissor em relação ao trator (4 posições)

- calibração do valor de leitura da antena receptora

- posicionamento da antena receptora (parte anterior do capo do trator, P1 e teto da cabina, P2).

\section{RESULTADOS E DISCUSSÃO}

\section{Parâmetros construtivos}

Antena do transmissor (TA): A análise dos resultados permitiu verificar-se uma relação direta entre o comprimento da antena e a intensidade da transmissão (espaço e valor da tensão de recepção em cada ponto). Considerando-se as exigências relativas à transmissão do sinal, por parte do transmissor em uma área relativamente ampla (um raio no plano horizontal de cerca de 15 a 20 m) escolheu-se a medida intermediária, $17,5 \mathrm{~cm}$.

Posicionamento da antena sobre o transmissor: Foi possível definir-se uma relação "qualitativa" entre este componente e o local onde se deve efetuar a transmissão. Considerando-se as duas disposições, a antena na parte central do transmissor foi a que apresentou melhores resultados.

Antena A1 da unidade receptora: Neste caso, os ensaios foram realizados levando-se em conta principalmente os aspectos funcionais do sistema em si, e não os relativos à própria antena; assim, por razões práticas e se considerando a instalação da antena receptora sobre o trator, não é possível usar-se antenas de forma ou dimensões tais que possam constituir-se em obstáculo na estrutura do trator, ocorrendo riscos de danos na própria antena, ou na visibilidade do tratorista. Uma antena com comprimento de $47 \mathrm{~cm}$ poderia ser escolhida, mas se optou, depois de um estudo de diversos modelos, por uma antena flexível, com $19 \mathrm{~cm}$ de comprimento .

Posicionamento da antena receptora (A1) no trator: Os ensaios realizados ofereceram indicações úteis sobre o projeto do sistema. A posição frontal (em cima do capo do trator) parece ser muito boa, considerando-se: a visibilidade (não atrapalha a visão do tratorista, mesmo no caso de trabalho com implemento de engate dianteiro); pouca possibilidade de quebra (menor em relação ao posicionamento sobre o teto da cabina; e mais fácil de controlar as perturbações devidas à influência da massa metálica sobre o campo eletromagnético).

Reconhecimento da máquina (TM): Os ensaios realizados foram suficientes para verificar a transmissão efetiva, do código de reconhecimento do implemento (TM) no local de trabalho, de acordo com a análise qualitativa do sinal.

Posicionamento da Antena A2: Tanto o ensaio para a verificação do sinal como o ensaio de posicionamento da antena receptora, não demonstraram problemas com relação à posição da antena, 
A2. Os ensaios que forneceram melhores resultados foram os obtidos na posição sobre a cabine. Estudou-se a simetria do sinal e a interferência. Nesta posição, o estilete da antena foi inclinado diretamente, em relação ao implemento. Com este procedimento, além de se obter uma recepção melhor, a própria antena ficou menos vulnerável a acidentes.

No que diz respeito ao reconhecimento do operador, não foi necessário realizar-se ensaios no campo, uma vez que a solução adotada para o transmissor $\mathrm{TO}$, que foi acoplado à chave de partida do trator, é muito utilizada em outros setores.

\section{Parâmetro funcional}

Este parâmetro concorre para definir o espaço tridimensional relativo à recepção dos sinais, segundo o código de reconhecimento de cada objeto. A regulagem do valor deste parâmetro constitui-se e será numa atividade muito delicada para o funcionamento de todo o sistema.

\section{Parâmetros do projeto do sistema}

Os ensaios realizados permitiram verificar-se os seguintes efeitos do suporte sobre a transmissão:

- variação da simetria radial do diagrama de irradiação

- variação da forma e intensidade de transmissão sobre o plano vertical

Houve interação entre o transmissor e o suporte, em que este mostrou influência em relação à direção dos sinais, característica muito importante para o funcionamento de todo o sistema. Considerando-se esta característica, é possível direcionar-se o sinal através do local onde o trator passar junto à unidade de recepção (entrada e saída do campo).

Quanto à robustez do conjunto transmissor/ suporte, optou-se pelo perfil em ferro, com dimensões tais que seja possível resistir às pancadas ocasionais causadas pelo trator em manobra $\mathrm{e}$ que, ao mesmo tempo, não apresentem problemas de custo e peso do material. Na versão empregada na instalação da fazenda, usou-se um suporte com apoio, para facilitar o deslocamento do instrumento. A visibilidade do suporte foi aumentada devido a pintura nele utilizada, que permitiu sua identificação pelo tratorista, a distância.

\section{Ensaio da interação trator-transmissor}

Esses ensaios permitiram verificar-se, pelo menos quantitativamente, as perturbações ocasionadas pela massa metálica do trator sobre a área de transmissão dos sinais. Estas perturbações consistiram na modificação da forma da onda de irradiação, e não no aparecimento, em alguns pontos (pontos cegos) do sinal devido ao efeito da massa de alguns componentes do trator (rodas, escape, radiador etc.); tais dados são de difícil elaboração matemática (variáveis dificilmente parametrizadas); entretanto, são de fundamental importância para indicar ao técnico o momento da instalação do equipamento no campo.

\section{CONCLUSÕES}

O sistema proposto superou a fase de construção de protótipos e esta sendo submetido a experimentação de campo. Estão sendo avaliadas soluções alternativas para melhor direcionar a transmissão do código da fonte, pretendendo-se diminuir o número de leituras acidentais; assim, otimiza-se a autonomia da memória sobre a DRT, enquanto a fase seguinte prevê o funcionamento definitivo de todo o sistema procurando-se aperfeiçoar o software de gerenciamento. Estuda-se a possibilidade de se fazer a interface deste sistema com os dados provenientes do sistema de informação paralelo, eventualmente existente na propriedade agrícola. De modo geral, a interface mais interessante pode prever a centralização dos dados agrometeorológicos da propriedade; o arquivo eventual das informações utilizadas no escritório, onde se verifica, com maior precisão, o fluxo interno dos fatores produtivos.

\section{LITERATURA CITADA}

Auernhammer, H. The German standard for electronical tractor implement data communication. Agrotique 89. Proceedings of the $2^{\text {nd }}$ International Conference, Bordeaux (France), 1989. p.395-402.

Auermhammer, H. Requirements for a standard for trator-implement communications. International ASAE Winter Meeting, Chicago, Illinois, Paper N. 951532. ASAE, St. Joseph, 1993.

Bosch, R. Gmbh. CAN Specification, Version 2.0. Stuttgart, Germany, September 1991.

Castelli, G.; Mazzetto, F. Automatic system for monitoring and recording farm field activities. In: International Conference on Computers in Agriculture, 4 ,1996, Cancum, Mexico, Anais... 1996, p.548-556.

Mazzetto, F. L'acquisicione dei datti aziendali in tempo reale. Genio Rurale, Milano, v.1, n.12, p.77-84, 1996.

Misener, G.G.; McLeod, C.D. A model to facilitate farm machinery use and cost data collection. Agricultural Systems, London, v.24, p.149-157, 1987.

Nicoletti, B. L'impiego degli elaboratori. In: Giacomazzi, F. "Manuale di gestione della produzione" Torino: ISEDI, 1975 v.34 n.1 p.34-27.

Stone, M.L.; Zachos, M. Aplication of J 1939 Networks in agricultural equipment. International ASAE Winter Meeting, Chicago, Illinois, Paper N. 931530. ASAE, St. Joseph, USA, 1993.

Young, S.C.; Sokol, D.G.; Strosser, R.P. Utilization of CAN technology in a distributed control system. International ASAE Winter Meeting, Chicago Illinois, Paper N. 931535. ASAE, St. Joseph, USA, 1993. 